\title{
Induction of apoptosis and inhibition of cell growth by tbx5 knockdown contribute to dysmorphogenesis in Zebrafish embryos
}

Jenher Lu ${ }^{1,2^{*}+}$, Tzuchun Tsai ${ }^{2,3}$, Sielin Choo ${ }^{4}$, Shuyu Yeh ${ }^{4}$, Renbing Tang ${ }^{1,2}$, Anhang Yang ${ }^{1,2}$, Hsinyu Lee ${ }^{5}$ and Jennkan $\mathrm{Lu}^{4 \dagger}$

\begin{abstract}
Background: The tbx5 mutation in human causes Holt-Oram syndrome, an autosomal dominant condition characterized by a familial history of congenital heart defects and preaxial radial upper-limb defects. We report aberrant apoptosis and dormant cell growth over head, heart, trunk, fin, and tail of zebrafish embryos with tbx5 deficiency correspond to the dysmorphogenesis of tbx5 morphants.
\end{abstract}

Methods: Wild-type zebrafish embryos at the 1-cell stage were injected with $4.3 \mathrm{nl}$ of $19.4 \mathrm{ng}$ of tbx5 morpholino or mismatch-tbx5-MO respectively in tbx5 morphants and mismatched control group. Semi-quantitative RT-PCR was used to for expression analysis of apoptosis and cell cycle-related genes. TUNEL and immunohistochemical assay showed the apoptosis spots within the local tissues. Ultra-structure of cardiac myocardium was examined by transmission electron microscope.

Results: Apoptosis-related genes (bad, bax, and bcl2), and cell cycle-related genes (cdk2, pcna, p27, and p57) showed remarkable increases in transcriptional level by RT-PCR. Using a TUNEL and immnuohistochemical assay, apoptosis was observed in the organs including the head, heart, pectoral fins, trunk, and tail of tbx5 knockdown embryos. Under transmission electron microscopic examination, mitochondria in cardiomyocytes became swollen and the myocardium was largely disorganized with a disarrayed appearance, compatible with reduced enhancement of myosin in the cardiac wall. The ATP level was reduced, and the ADP/ATP ratio as an apoptotic index significantly increased in the tbx5 deficient embryos.

Conclusion: Our study highlighted that tbx5 deficiency evoked apoptosis, distributed on multiple organs corresponding to dysmorphogenesis with the shortage of promising maturation, in tbx5 knockdown zebrafish embryos. We hypothesized that mesenchymal cell apoptosis associated with altered TBX5 level may subsequently interfered with organogenesis and contributed to dysmorphogenesis in tbx5 deficiency zebrafish embryos.

Keywords: zebrafish, mitochondria, apoptosis, tbx5, Holt-Oram syndrome, cell cycle

\section{Background}

Tbx5 belongs to the T-box family of transcription factors and is required for the embryonic development of the heart and forelimbs [1,2]. Tbx5 mutations in humans cause Holt-Oram syndrome (HOS), an autosomal dominant condition characterized by a familial

\footnotetext{
* Correspondence: jenherlu@gmail.com

+ Contributed equally

'Department of Pediatrics and Pathology, Taipei Veterans General Hospital,

Taipei, Taiwan

Full list of author information is available at the end of the article
}

history of congenital heart defects and preaxial radial ray upper-limb defects $[3,4]$. The phenotypic manifestations of $t b x 5$ deficiency in different vertebrates are quite similar. Tbx5 deficiency in zebrafish causes multiple organ defects during organogenesis, including a shortened trunk, failure of cardiac looping formation, and hypogenesis or agenesis of the pectoral fins $[5,6]$. Either the type of mutation or the location of a mutation is predictive for the severity of heart or limb malformations in Holt-Oram syndrome patients. That is, there is

\section{() Biomed Central}

(c) 2011 Lu et al; licensee BioMed Central Ltd. This is an Open Access article distributed under the terms of the Creative Commons Attribution License (http://creativecommons.org/licenses/by/2.0), which permits unrestricted use, distribution, and reproduction in any medium, provided the original work is properly cited. 
no correlation between the $t b x 5$ genotype and phenotype.

Since $t b x 5$ encodes a transcription factor, $t b \times 5$ deficiency is presumed to disrupt development by altering the transcriptional function of the TBX5 protein, thereby affecting downstream target gene expressions, particularly affiliation binding proteins or transcription factors [7-9]. Though TBX5 is an important developmental regulator in normal development and disease, which TBX5 functions or whether the TBX5 protein plays a role as trasnscriptional activator or repressor, even divergent in different condition, is still relatively unclear.

The syndrome caused by mutations in T-box transcription factor 5 (TBX5) was described as "premature stops" or "developmental delay" in embryogenesis, though the mechanism how to delay or stop the development of the embryo, especially the cardiogenesis, remained indistinct [10]. Some revealed that the depletion of $t b \times 5$ leading to cardiac cell cycle arrest have been proved to elicit defect in cardiac sacromere formation and decreased cardiac cell number [11].

Apoptosis is a key event in many biological processes including embryogenesis and occurs in a variety of circumstance in specific time window in embryos. Zebrafish undergoes different levels of developmental cell death throughout embryonic stages precisely, including brain, spinal cord, ear, eyes, germ cells, tail bud and excretory system [12]. Apoptosis partakes in the complicate orchestration cell-cell interaction during organogenesis, such as cell differentiation in heart myocardium and the endocardial cushions during specific time [13]. Some postulated that anomalous apoptosis due to insufficient or improper induction of organogenesis specific factors leads to particular congenital diseases [14].

In this study, we reported that aberrant apoptosis and cell cycle arrest are increasing in zebrafish embryos with $t b x 5$ deficiency; meanwhile, the excessive apoptosis is in coincidence with the dysmorphogenesis in individuals with $t b x 5$ deficiency.

\section{Materials and methods}

The approval of this study was granted by the National Taiwan Ocean University Aquaculture Animal ethics review board with annual evaluation.

\section{Maintenance of zebrafish}

Zebrafish were maintained in 45-liter aquaria heated to $28.5^{\circ} \mathrm{C}$ with 25 fish per tank. The water was filtered, and about half of the water was replaced at least once a week. Adult zebrafish were fed 1 or 2 times per day with a variety of food, and the tank was cleaned by siphoning off any excess food after the second daily feeding. The day-night cycle was controlled with an automatic timer (14 h light/10 h dark).

\section{Breeding of zebrafish}

Zebrafish reach sexual maturity in $10 \sim 12$ weeks, but breeding fish should be between 7 and 18 months of age for maximum embryo production. The day before breeding, 1/3 of the water was replaced and the tank was cleaned after feeding ( $1 \sim 2 \mathrm{~h}$ before the end of the light period). Finally, a collection box was placed at the bottom of the tank and preparation was made to collect the embryos the next day.

\section{Embryo collection}

When the light came on, we removed the collection box and placed the collected embryos into an incubator maintained at a temperature of $28.5^{\circ} \mathrm{C}$.

\section{RNA isolation}

Total RNA was isolated from 50 embryos using the guanidine isothiocyanate-based TRIzol solution. RNA samples were resuspended in DEPC-treated water and quantified spectrophotometrically at $260 \mathrm{~nm}$. The RNA quality was then checked by $1.2 \%$ agarose gel electrophoresis, after staining with $1 \mu \mathrm{g} / \mathrm{ml}$ ethidium bromide. The RNA stock was stored at $-80^{\circ} \mathrm{C}$.

\section{Semi-quantitative Reverse-Transcriptase Polymerase Chain Reaction}

Total RNA was prepared from 50 morpholino (MO) injected or normal embryos (Invitrogen Corporation, Carlsbad, CA, USA). Three microliters of 1st-strand cDNA was amplified. Amplification primers for each specific mRNA were deduced from published sequences and included bcl2 (P1: 5'-GTTCCACCCGTTTTCA-3', P2: 5'-GCGAGTCCTCATTCTGT-3'), bad (P1: 5'-CA AGCCTGGATAAACAC-3', P2: 5'-GGCAGATTGAAAGAAAG-3'), and $b a x$ (P1: 5'-AAGCATTGAGAGGTG3', P2: 5'-AGAGGAAGTGAGGAGAA-3'), p27 (P1: 5'GTTCGCTTGTCTAATGG-3', P2: 5'-GTCGGACTCAATGGTT-3'), p57 (P1: 5'-AGATTACGAGTGGGAGG-3', P2: 5'-TGAGTTCAGAGAGAAAGGG-3'), and pcna (P1: 5'-GCTCGCGGGATTTCT-3', P2: 5'CAGCGGAGTGGCTTTGG-3'), $c d k 2$ (P1: 5'-CAAGAGTTTCAGTCGC-3', P2: 5'-TAAGTCCGCACAGGTA - $\left.3^{\prime}\right)$. PCR conditions were as follows: denaturation at $95^{\circ} \mathrm{C}$ for $3 \mathrm{~min}$, followed by 50 cycles of amplification $\left(95^{\circ} \mathrm{C}\right.$ for $20 \mathrm{~s}, 59^{\circ} \mathrm{C}$ for $15 \mathrm{~s}$, and $72^{\circ} \mathrm{C}$ for $20 \mathrm{~s}$ ). Quantification of PCR product was performed on an electrophoresis agarose gel using Kodak image 3.5 software. All measurements were performed in triplicate $(n=3)$.

\section{Microinjection and morpholino treatment}

The morpholino antisense oligonucleotide, $t b x 5$-MO $(5$ GAAAGGTGTCTTCACTGTCCGCCAT-3), was designed against the $t b x 5$ translational start site (Gene 
Tools LLC, Philomath, OR, USA) and a mismatch $t b \times 5$ MO (5'-GTCTCTTGACTCTCCGCGATCTCGG-3') was designed for control (Gene Tools LLC, Philomath, OR, USA). Wild-type embryos primarily at the 1-cell stage with the chorion intact were injected with 19.4 $\mathrm{ng} / 4.3 \mathrm{nl}$ of stock morpholino diluted in Danieau's solution. The injected embryos were raised at $28.5^{\circ} \mathrm{C}$. Embryos used for analyzing the expression of various markers were fixed with $4 \%$ paraformaldehyde. Otherwise, embryos were scored after 2 days of development for late effects. In our previous study, three control groups, including $3^{\prime}$ end of $t b x 5-\mathrm{MO}(2)$ (5'-GCCT GTACGATGTCTACCGTGAGGC-3') and embryos with blank microinjection and wild-type ones without microinjection, were included to identify the specific blockage of $t b x 5$ mRNA translation effect of $t b \times 5-\mathrm{MO}{ }^{6}$ In order to examine the knockdown effectiveness of the $t b \times 5-\mathrm{MO}$, a $t b \times 5$-GFP construct was generated by fusing a 468-bp fragment of $t b x 5$, which included the morpholino target side into a GFP producing vector. $\mathrm{Tb} \times 5-\mathrm{MO}$ at $19.4 \mathrm{ng}$ and $t b \times 5$-GFP DNA at $150 \mu \mathrm{g}$ were coinjected into 1-cell stage embryos. In control group, only $150 \mu \mathrm{g}$ of $t b \times 5$-GFP was microinjected into 1-cell stage embryos [6].

\section{Immunohistochemical analysis}

Zebrafish embryos were fixed with 4\% paraformaldehyde in phosphate-buffered saline (PBS). Deparaffinized sections $(3 \mu \mathrm{m})$ of zebrafish embryo tissues were placed on slides and processed for immunohistochemistry. After blocking with a biotin blocking system (Dako A/S, Glostrup, Denmark) for $30 \mathrm{~min}$, sections were incubated with target-purified rabbit primary antibodies, including BCL2 (Anaspec Inc., Fremont, CA, USA), BAD (Anaspec Inc., Fremont, CA, USA), CASPASE-3 (Anaspec Inc., Fremont, CA, USA), CASPASE-8 (Anaspec Inc., Fremont, CA, USA),

CDK2 (Anaspec Inc., Fremont, CA, USA), P27 (Anaspec Inc., Fremont, CA, USA) and MF20 (Developmental Studies Hybridoma Bank, Iowa City, IA, USA), washed in PBS, and then incubated with a rhodamineconjugated secondary antibody: goat anti-rabbit immunoglobulin G (IgG). After washing in PBS, sections were incubated with mounting medium and kept at $4{ }^{\circ} \mathrm{C}$.

\section{Transmission electron microscopic examinations}

Embryos were fixed at $48 \mathrm{~h}$ post-fertilization (hpf) with $2.5 \%$ glutaraldehyde in Sorenson's phosphate buffer, postfixed with $1 \% \mathrm{OsO}_{4}$ in Sorenson's phosphate buffer followed by dehydration through a graded series of ethanol washes, and embedded in Spurr's EPON. Blocks were heated in an oven for $8 \mathrm{~h}$ at $70^{\circ} \mathrm{C}$. Semithin (1$\mu \mathrm{m})$ sections were cut and stained with toluidine blue for adequate preview under a microscope. Ultrathin sections (900 $\AA$ ) were cut with a diamond knife, stained with uranyl acetate and lead citrate, and examined with an electron microscope.

\section{TUNEL assay}

Both whole mount and sectioned TdT-UTP nick end labeling (TUNEL) assays were performed using an ApopTag kit (Chemicon, Heule, Belgium). Briefly, zebrafish embryos were fixed with $4 \%$ paraformaldehyde in PBS. Proteinase K-treated whole embryos or deparaffinized sections $(5 \mu \mathrm{m})$ of embryos were incubated with the TdT enzyme followed by anti-digoxigenin. Finally, embryos or slides were stained with DAB for $5 \mathrm{~min}$.

\section{Western blot analysis}

Embryos were homogenized on ice in lysis buffer (Sigma-Aldrich, St. Louis, MO, USA). Then, cellular debris was pelleted by centrifugation at 12,000 rpm for $20 \mathrm{~min}$, and the supernatant was collected and measured. Proteins were mixed with sample buffer before separating in 10\% sodium dodecylsulfate polyacrylamide gel electrophoresis (SDS-PAGE) gels. The SDS-PAGE was then transferred onto nitrocellulose membranes at $100 \mathrm{~V}$ for $1 \mathrm{~h}$. Membranes were blocked with blocking buffer ( $5 \%$ bovine serum albumin (BSA)) at room temperature for $1 \mathrm{~h}$. The TBX5 primary antibody (Aviva Systems Biology LLC, San Diego, CA, USA) was incubated overnight at $4^{\circ} \mathrm{C}$ using the appropriate dilution (1: 1000). The nitrocellulose membranes were washed with PBST followed by incubating with a horseradish peroxidase (HRP)-conjugated secondary antibody (1: 5000) for $1 \mathrm{~h}$ at room temperature before the images were digitized.

\section{ADP/ATP Ratio}

ATP and ADP/ATP ratio assay were performed using an ApoSENSORTM ADP/ATP Ratio Assay Kit (Biovision, Mountain View, CA, USA). Ten embryos $(n=10$ in each subgroup) were separately placed in 96-well roundbottomed, flat, white plates for detection. The RLU (relative luminescence unit) value was detected using the PARADIGMTM Detection Platform (Beckman Coulter Inc., Brea, CA, USA).

\section{Statistical analysis}

Results are given as the mean \pm S.D. Where applicable, a $t$-test was performed. Statistical significance was accepted at $p<0.05$.

\section{Results}

Morphological characteristics of tbx5 knockdown embryos

The normal cardiac looping process was completed in wild-type (WT) embryos at $48 \mathrm{hpf}$, meanwhile the 
ventricle overlapped with the atria during the diastolic phase (Figure 1A). Injection of the $t b \times 5$ morpholino (MO) directly into embryos at the 1-cell stage resulted in retardation of the looping process, and the most prominent cardiac finding in $t b x 5$ morphants was a stringlike heart (Figure 1B). At 96 hpf, WT embryos had a pair of well-formed pectoral fins (Figure 1E); however, the pectoral fins of $t b x 5$ knockdown embryos showed hypoplasia or even agenesis (Figure 1F). The tail (Figure $1 \mathrm{~J}$ ) and trunk (Figure 1N) of knockdown embryos were shortened and distorted in shape, while WT embryos had a straight tail (Figure 1I) and trunk (Figure 1M), both of which were longer.
TUNEL assay of tbx5 knockdown embryos

We examined apoptosis using a TUNEL assay. Aberrant poptosis was present in the entire paravertebral mesenchymal zone of $t b x 5$ knockdown embryos (Figure $1 \mathrm{H}, \mathrm{Q})$. Apoptosis was noted in the heart (Figure 1D), tail (Figure 1L), bilateral paravertebral mesenchymal region (Figure $1 \mathrm{H}$ ) and trunk (Figure 1Q) of $t b \times 5$ knockdown embryos. Apoptosis also slightly noted in the pericardium (Figure $1 \mathrm{C}$ ), tail (Figure $1 \mathrm{~K}$ ), bilateral paravertebral mesenchymal region (Figure $1 \mathrm{G}$ ) and trunk (Figure 1O) of WT embryos. Furthermore, there was no significant difference between WT and mismatch-tbx5-MO treated embryos (Figure 1P).

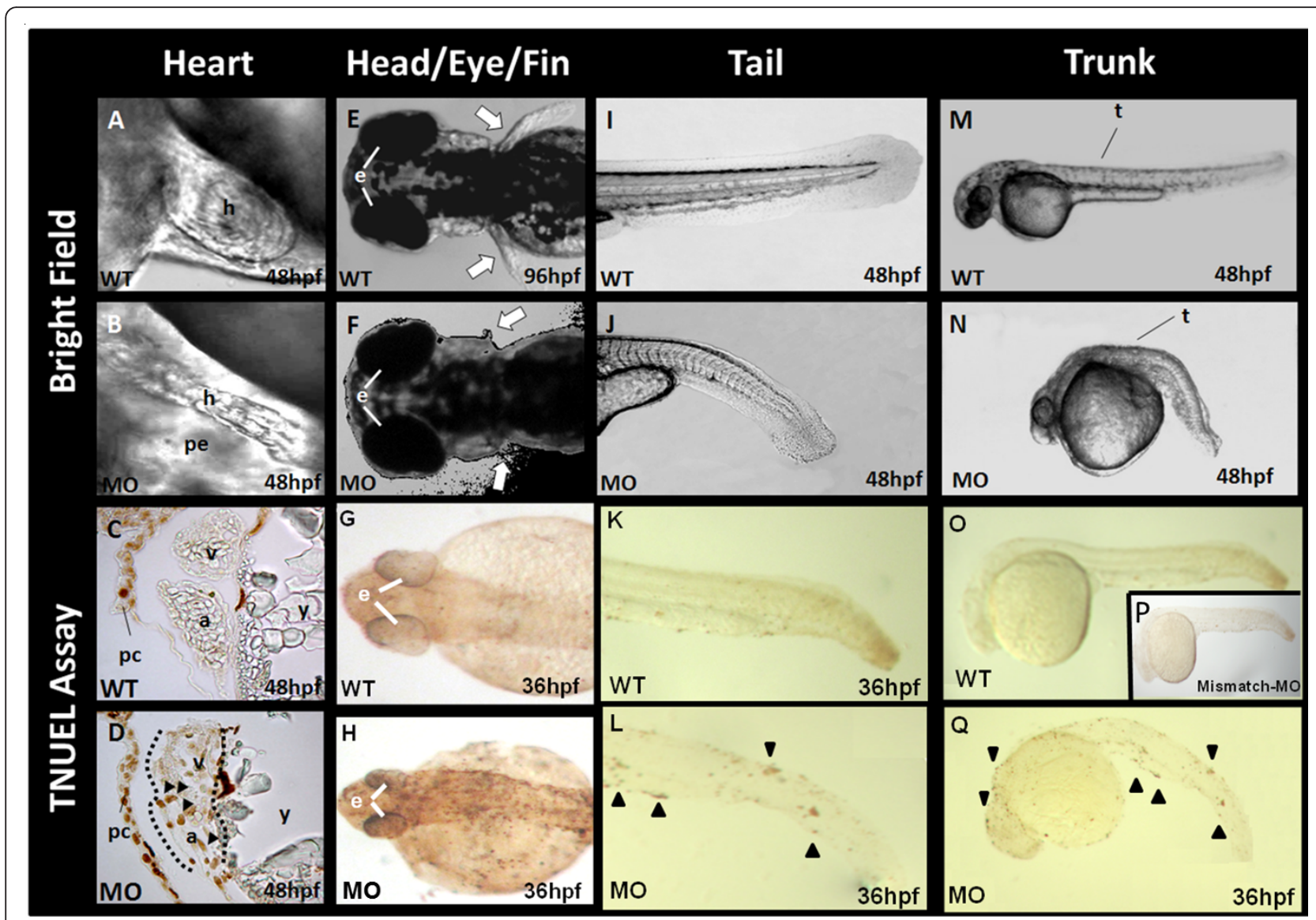

Figure 1 Morphological changes and the TUNEL assay of tbx5 knockdown embryos. A: In wild-type (WT) embryos, the atrium and ventricle overlap due to normal looping formation. The heart is located in the cardiac sac. B: In tbx5 knockdown embryos, a string-like cardiac morphology was observed, with no looping formation. Most of the cardiac sac was occupied by pericardial effusion. C: No apoptosis was observed in the atria or ventricle of WT embryos, but a little apoptosis was noted in the pericardium. D: Apoptosis occurred in the heart of tbx5 knockdown embryos accompanied by significant apoptosis in the pericardium. E-F: Symmetrical development of bilateral pectoral fins was observed in WT embryos (E); however, pectoral fins of tbx5 deficient embryos were hypoplasia (F). G: Trivial apoptosis was observed in the eyes, head, and the bilateral paravertebral mesenchymal region of WT embryos. H-J: Prominent apoptosis was detected in knockdown embryos $(\mathrm{H})$. Compared to WT embryos (I, M), a shortened and curled malformed trunk was present in tbx5 knockdown embryos (J, N). K-Q: Prominent apoptosis was located along the curled tail $(\mathrm{L})$ and trunk $(\mathrm{Q})$ of tbx5 deficiency embryos, while normal embryos and mismatch-tbx5-MO injected embryos had a straight tail $(K)$ and trunk $(\mathrm{O}, \mathrm{P})$. A-Q: The anterior of the embryos is to the left. A-B, I-Q: Lateral view; E-F: dorsal view; G-H: anterior view; C, D: Sagittal section. h, heart; pe, pericardial effusion; a, atrium; v, ventricle; y, yolk; t, trunk; white arrow, pectoral fin; black triangle, location of apoptosis; hpf, hour post fertilization; MO, tbx5-MO treated embryos. 
Molecular characteristics of $t b \times 5$ knockdown embryos Tbx 5 knockdown zebrafish embryos were used by microinjecting $19.4 \mathrm{ng} / 4.3 \mathrm{nl}$ of $t b \times 5-\mathrm{MO}$ at $0 \mathrm{hpf}$ as described in our previous study [6]. The efficiency of the $t b x 5-\mathrm{MO}$ was confirmed both with Western blotting (Figure 2A) and $t b x 5$-green fluorescent protein (GFP) construct [6].

We tested the expressions of apoptosis-related genes at 3 important developmental periods in both WT and MO-treated zebrafish embryos: heart tube formation at $24 \mathrm{hpf}$, looping formation at $30 \mathrm{hpf}$, and chamber formation at $48 \mathrm{hpf}$. Cell apoptosis-related genes, including $b a d, b a x$, and $b c l 2$, showed remarkable increases in $t b x 5$ morphants in all studied periods but not in embryos injected with mismatch-tbx5-MO, which has no significant different with the wild-type and control mismatch (Figure 2B-D).

By semi-quantitative PCR methods, the depletion of tbx 5 caused an increase of the expression of S stagerelated mRNA: $p 27$ and $p 57$ (Figure 3A, B), and the significant increases in $c d k 2$ and pcna (Figure $3 \mathrm{C}, \mathrm{D}$ ) expressions in $t b x 5$ morphants. It suggested prolongation of the G1/S phase, which imply interfered cell cycle and reduction in cell number in $t b \times 5$ morphants.

\section{Immunohistochemical analysis}

The apoptosis downstream factor, CASPASE- 8 and CASPASE-3, plays vital role in both cell intrinsic and extrinsic apoptosis. CASPASE- 8 and CASPASE- 3 was induced in the heart of $t b \times 5$ knockdown embryos at $48 \mathrm{hpf}$, which suggests the occurrence of apoptosis which might via activation of CASPASE-8 and therefore activates its downstream factor CASPASE-3 (Figure 4A-D).

The overexpression of the apoptosis-related and cellcycle-related protein, BAD (Figure 4E, F), BCL2 (Figure 4G, H), CDK2 (Figure 5A, B), P27 (Figure 5C, D) was confirmed by an immunohistochemical analysis. Cardiomyogenesis plays vital roles in different stages includes heart looping, chamber formation, and ballooning. Our study demonstrated that the expression of myosin, stained by the anti-cardiac myosin antibody, MF20, was reduced in $t b x 5$ knockdown embryos (Figure 6A-F).
A

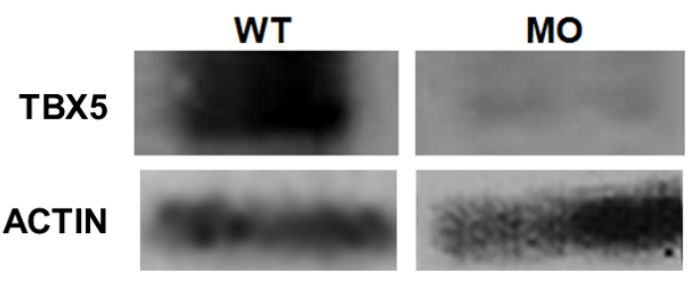

B

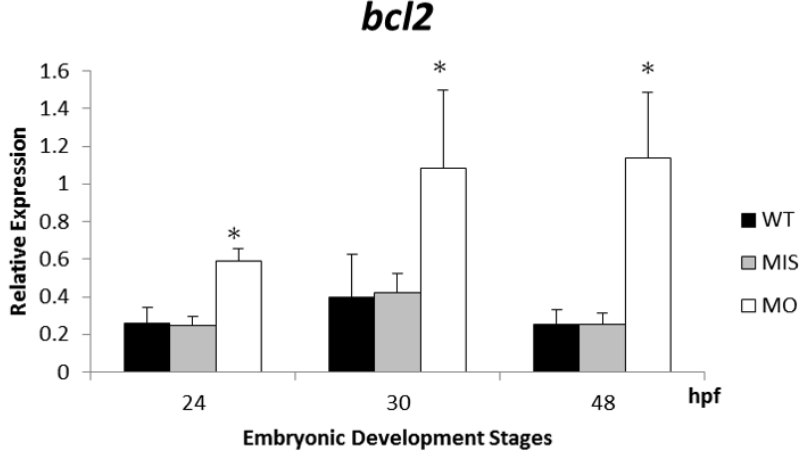

D

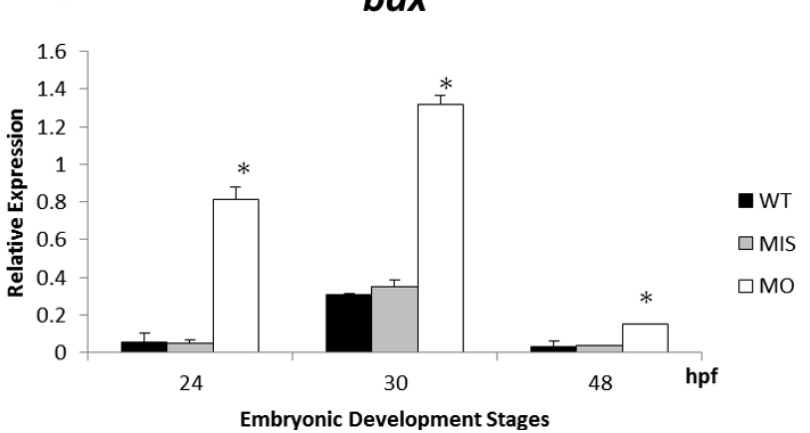

Figure 2 Quantification of apoptosis-related gene expressions in tbx5 deficiency zebrafish embryos using a semi-quantitative PCR. A: The efficiency of the tbx5-MO was tested using Western blot. Tbx5-MO remarkably inhibited the expression of the TBX5 protein ( $n=3,100$ embryos). B-C: The proapoptotic genes, bad (B) and bax (C), were significantly activated in tbx5-MO-treated embryos. D: The antiapoptosis gene, $b c \mid 2$, was significantly induced in tbx5 knockdown embryos throughout the developmental stages $(n=3,50$ embryos/stage; relative expression, gene expression/ $\beta$-actin expression). Data are presented as the mean \pm S.D. An asterisk indicates a significant difference $(p<0.05)$. 


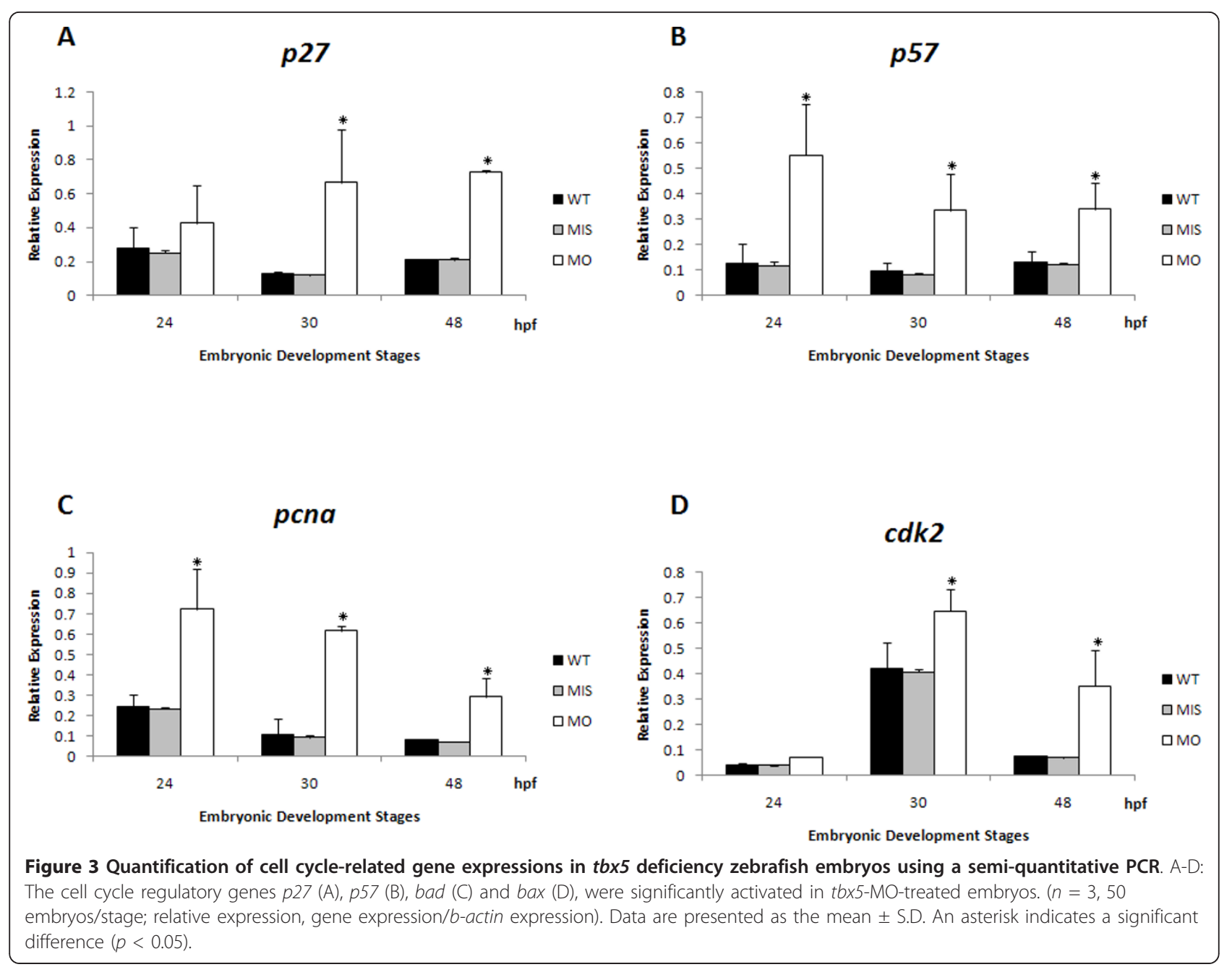

\section{Ultrastructural changes in mitochondria}

The mitochondrion is the center of the cell intrinsic apoptosis pathway, and the ultrastructure of mitochondria was markedly changed in tbx5 morphants. Mitochondria are normally compact in WT group (Figure 7A) but become swollen in $t b x 5$ knockdown embryos (Figure 7B). The mitochondrial size of WT embryos was $1.64 \pm 0.4 \mu \mathrm{m}^{2}$, while swollen mitochondria were $5.91 \pm$ $1 \mu \mathrm{m}^{2}$ (Figure 7E). Additionally, the amount of mitochondria remarkably increased in $t b \times 5$ knockdown embryos $\left(8.33 \pm 2.1\right.$ vs. $\left.2.67 \pm 0.6 / 25 \mu \mathrm{m}^{2}\right)$ (Figure $\left.7 \mathrm{~F}\right)$.

\section{Ultrastructural changes in cardiac myofibrils}

Normal cardiac myofibrils were well organized as the Zdisc and M-lines in WT embryos at $48 \mathrm{hpf}$ (Figure 7C). In contrast, the ultrastructure of the myocardium appeared largely disorganized in tbx5 knockdown embryos. In addition, myofibrils appeared to be disarrayed (Figure 7D). Furthermore, cardiocytes were disaggregated and failed to develop a tight junction to each other. (Figure 7A-B) The myofibril layer in the cardiac chamber wall had become very thin with a disarrayed arrangement (data not shown).

\section{Changes in the ADP/ATP ratio}

The ratio of ADP/ATP has been used to distinguish if cells have undergone cell death or proliferation; an increase in the ADP/ATP ratio is recognized in an apoptotic state. We analyzed both the ATP level and ADP/ATP ratio in $t b x 5$ deficient embryos at $48 \mathrm{hpf}$. The ATP level of $t b x 5$ knockdown embryos $(n=10$ in each subgroup) was remarkably decreased (Figure 8A). Furthermore, a high ADP/ATP level in $t b \times 5$ knockdown embryos indicated the occurrence of apoptosis (Figure 8B).

\section{Discussion}

Organogenesis is a vital process during embryonic development and is often accompanied by apoptosis in certain time windows. Vertebrate embryos, including 


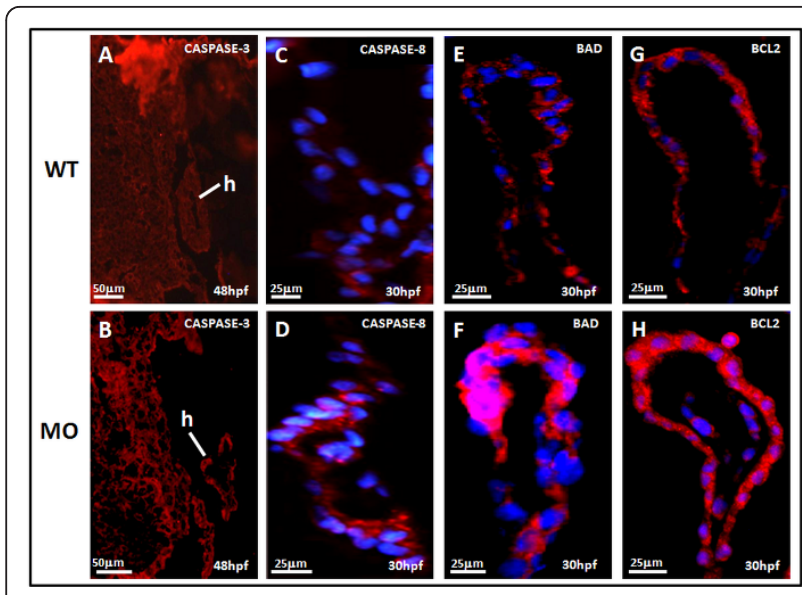

Figure 4 Sagittal view of the heart in $t b \times 5$ knockdown embryos by immunohistochemical studies of heart. A-B

Caspase-3 (red) expression could been slightly seen in wild-type (WT) embryos (A), but caspase-3 was more induced in knockdown embryos at $48 \mathrm{~h}$ post-fertilization ( $\mathrm{hpf}$ ) though the expression was not so strong (B). Caspase-8 (blue) was more induced in knockdown embryos (D) at $48 \mathrm{~h}$ post-fertilization (hpf) than the expression in wild-type (C). The proapoptotic factor, BAD (red), was enhanced in tbx5 deficiency embryos (F) with the nucleus stained by DAPI (blue); but there was almost no BAD expression in WT embryos (E).

Compared to the WT $(G)$, embryos with tbx5 deficiency showed a significant increase in BLC2 expression $(H)$. The anterior of embryos is to the left. $\mathrm{h}$, heart; $\mathrm{MO}$, tbx5-MO-treated embryos.

those of zebrafish, undergo programmed cell death throughout the development process $[15,16]$. Development of an organ or tissue is often preceded by the extensive proliferation and differentiation of a particular cell; the resultant mass is then "pruned" into the correct form by apoptosis. Therefore, embryonic development is strictly regulated by processes including cell proliferation, migration, differentiation, and apoptosis. Dysregulation of any of the processes can cause congenital diseases and anomalies. Previous evidence showed the important roles of apoptosis in embryonic cardiac development. Poelmann et al. reviewed how apoptosis occurs in the myocardium of the outflow tract and in the formation of the atrioventricular cushion, pulmonary trunk, semilunar valves, and even vascular remodeling [13]. Aberrant patterns, overactivation, or disruption of apoptosis can cause congenital malformations. For example, disorder of the apoptosis process impelled the regression of four-arch segments and interrupted aortic arch type B in tumor growth factor (TGF)- $\beta 2$-deficient mice [17].

Our data revealed activation of apoptosis and inhibition of cell growth in embryonic tbx5 morphants at 36 hpf by transcriptional and translational levels. By RTPCR, the members of BCL-2 family genes and cell cycle-related genes were overexpressed in specific time window during zebrafish embryonic development. All

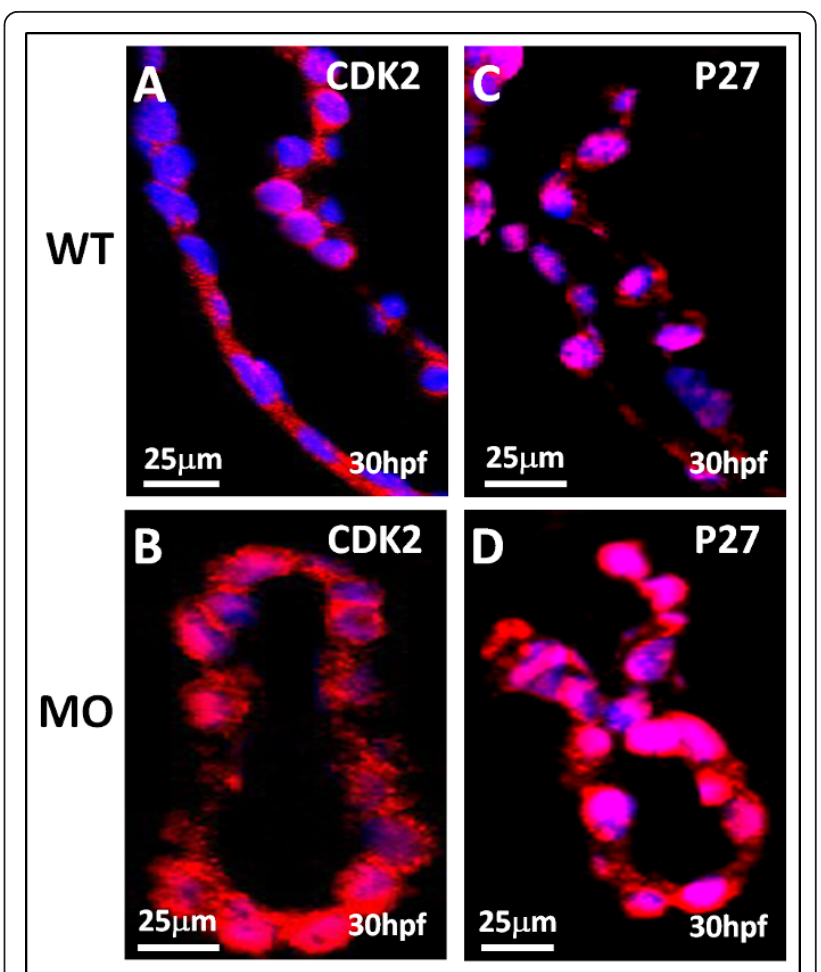

Figure 5 Immunohistochemical studies of heart sagittal sections in tbx 5 knockdown embryos by cell cycle-related antibodies. A-D: Both cell cycle-related factor CDK2 (red) (A) and P27 (red) (C) expressed mildly in WT embryos but was highly induced in tbx5 knockdown embryos (B, D) at $30 \mathrm{hpf}$. The nucleus was counterstained with DAPI. The anterior of embryos is to the left. h, heart; MO, tbx5-MO-treated embryos.

apoptosis related genes either anti-apoptosis related gene $(b c l-2)$ or pro-apoptosis related genes (bad and $b a x)$ were all transcriptionally activated, and so were the cell proliferation markers ( $c d k 2$ and $p c n a)$ and cyclin kinase inhibitors ( $p 27$ and $p 57)$. In protein level, remarkably plentiful production of apoptosis-related proteins including CASPASE-3, CASPASE-8, and BAD were proved by immunohistochemistry These data disclose that a deficiency of $t b x 5$, a transcription factor, in zebrafish embryos may trigger multiple signal pathways including promoting or inhibiting molecules and eventually come to the end sequel of apoptosis and cease of cell growth.

Besides, the distribution of aberrant apoptosis and deviant cell cycle caused by a deficiency of $t b x 5$ in the embryos might be associated with the dysmorphogenesis, especially engendering the string-like heart, short fins, and malformed trunk during zebrafish embryonic development.

There are two main apoptosis pathways including cellintrinsic (mitochondrial) pathway and cell-extrinsic (death receptor) pathway; the intrinsic pathway is largely 


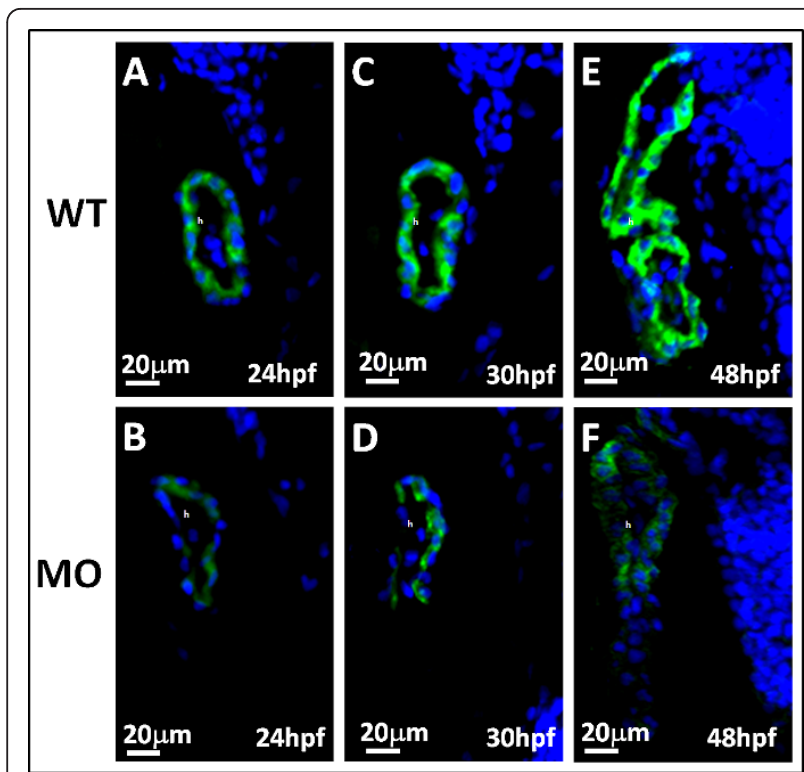

Figure 6 Myosin of zebrafish embryos was stained by the heart-specific anti-myosin antibody, MF20 (green), and counterstained by DAPI (blue) for nuclear observation. A-F: The expression of MF20 in embryos with tbx5 deficiency $(B, D, F)$ decreased throughout the developmental stages compared to that in the WT $(A, C, E)$, from 24 to $48 \mathrm{hpf}$. The anterior of embryos is to the left. $\mathrm{h}$, heart; $\mathrm{MO}$, tbx5-MO-treated embryos.

regulated by mitochondria, whereas the extrinsic pathway interacts with death receptors [18]. Mitochondria play fundamental roles in both life and death to provide factories of bio-energy and also gates of apoptosis for cells [19]. There is no exception in embryonic development. Mitochondria supply energy to embryos from the beginning of fertilization to ensure that the progressive development of an embryo is clearly documented $[20,21]$. The synthesis of ATP which is compulsory for maintaining regular cellular function was impaired during the mitochondrial apoptotic process and diminished cell viability [22-24]. In addition, resynthesis of ATP decreased in the mitochondria of apoptotic cells, and a relatively low ratio of ATP to ADP can be used to monitor apoptosis. The decreased ATP level suggests an inadequate energy supplement; furthermore, conversion of the ADP/ATP ratio indicates energetic exhaustion as a result of an apoptotic process in $t b \times 5$-deficient embryos at the late stage of organogenesis [25,26].

The mitochondrial apoptotic process causes the outer membrane of mitochondria to release proapoptotic proteins and eventually gives rise to swollen mitochondria $[27,28]$. Our ultrastructural findings by TEM revealed that mitochondria were swollen and loose in the hearts of tbx5 knockdown embryos, rather than small and dense in WT embryos. This phenomenon is compatible with the morphological changes of mitochondria during

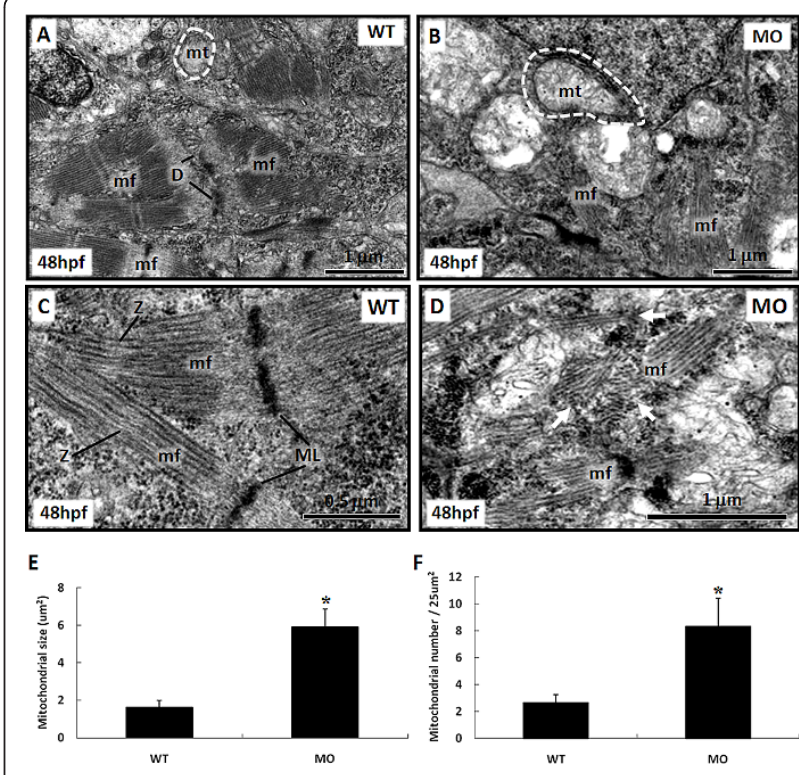

Figure 7 Ultrastructural changes of mitochondria and myofibrils in the heart of $t b \times 5$-knockdown and wild-type (WT) embryos at $48 \mathrm{~h}$ post-fertilization (hpf) under TEM. A: Small mitochondria and well-formed desmosomes can be observed in WT embryos. B: Multiple swollen mitochondria can be observed within myocytes of tbx5 knockdown embryos. C: Well-organized myofibrils with a $M$ line and $Z$ disc can be observed in normal embryos. D: Disarrayed myofibrils appeared in tbx5 knockdown embryos while the $\mathrm{M}$ line and $\mathrm{Z}$ disc were unrecognizable. $\mathrm{E}-\mathrm{F}$ : Both the size $(\mathrm{E})$ and number $(F)$ of mitochondria had significantly increased in tbx5 knockdown embryos. Data are presented as the mean \pm S.D. An asterisk indicates a significant difference $(p<0.05)$. mf, myofibril; mt, mitochondria; $\mathrm{D}$, desmosome; ML, M-line; Z, Z-disc; white arrow, disarrayed myofibrils; MO, tbx5 knockdown embryos.

apoptosis, which culminates in permeabilization of the mitochondrial outer membrane and release of soluble proteins from the mitochondrial intermembrane space. Once the mitochondrial permeability transition pore is opened, proapoptotic proteins are released, and the membrane potential collapses, which results in swelling of mitochondria. The number of mitochondria in $t b \times 5$ deficiency embryos also increased in addition to their size. Although a similar phenomenon was described during apoptosis induced by anticancer drugs in colon cancer cells and apoptosis in mitochondrial myopathy, mitochondrial proliferation accompanied by mitochondrial swelling was first reported in apoptosis of zebrafish embryos with $t b x 5$ deficiency [29]. Until now, the role of mitochondrial proliferation linked to apoptosis has remained unexplained.

Under TEM, the ultrastructure of the myocardium in tbx5 knockdown embryos appeared eminently disorganized. The myofibrils were quantitatively diminished at both the atrial and ventricular levels. We used MF20, an anti-myosin antibody, to prove a decrease in cardiac 

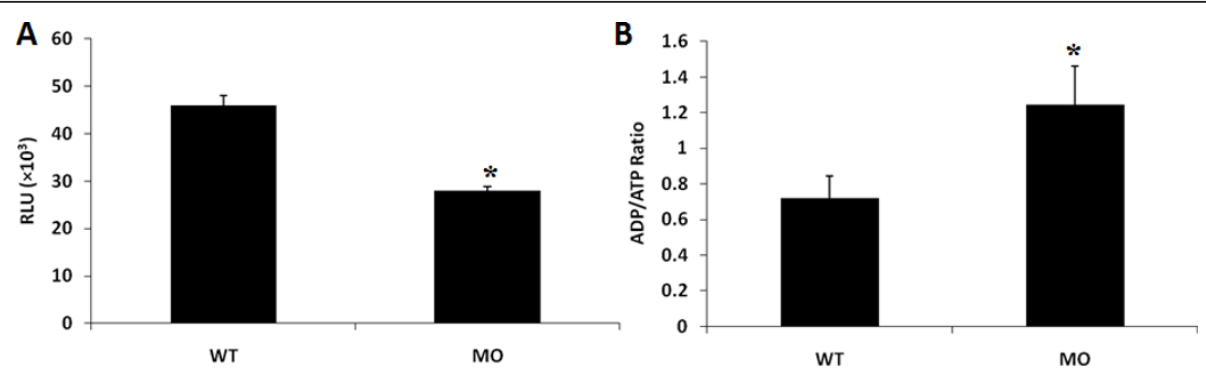

Figure 8 Changes in the ADP/ATP ratio in $\mathbf{t b x} \mathbf{5}$ knockdown embryos. A: In wild-type (WT) embryos, the ATP level was higher than that in tbx5 deficiency embryos. B: The ADP/ATP ratio of tbx5 knockdown embryos was significantly higher, indicated that apoptosis had occurred $(n=$ 10). Data are presented as the mean \pm S.D. An asterisk indicates a significant difference $(p<0.05)$. MO, tbx5 knockdown embryos.

myosin. This result is in accordance with conclusion of our previous study that cardiomyogenesis-related genes were perturbed in $t b x 5$ knockdown embryos [6].

The TUNEL assay showed that a shortage of $t b \times 5$ activated aberrant apoptosis and dormant cell growth in the head, heart, fins, and trunk. Although abnormal apoptosis-related genes were expressed throughout the entire process of organogenesis in $t b \times 5$ knockdown embryos, the degree and distribution of apoptosis varied in different locations at $48 \mathrm{hpf}$. Such aberrant apoptosis may contribute to consequent morphologic anomalies including a string-like heart, a curled trunk, and hypogenesis of the pectoral fins, but it did not interfere with the migration and differentiation of progenitor cells during early development. For example, no ectopic fin was found in embryos, although hypogenesis or agenesis of the pectoral fin was frequently observed in $t b x 5$ morphants, as was the string-like heart. We hypothesized that the aberrant apoptosis may play a role in the interruption of cardiac looping, chamber formation, and growth of pectoral fins in zebrafish. Nevertheless, mutations in $t b x 5$ gene underlie Holt-Oram syndrome, the majority of which is assumed as sequel "premature stops" or "developmental delay", may induce inappropriate apoptotic processes during embryogenesis and lead to the dysmorphogenesis including cardiac and limb malformation.

From a genomic analysis, dozens of genes were related to the underlying causes of isolated congenital heart disease and genetic syndrome associated with cardiac anomalies. However, genotype-phenotype distinctions exist. The discrepancy was frequently related to multiple genetic pathways, the size of the deletion, different allele/loci, point mutations, or a haploinsufficiency. Our observation presumed that the genotype-phenotype distinction might be a consequence of variable degrees of apoptosis in progenitor cells.

Some study declared that exogenous TBX5 could induce apoptosis and inhibit cell proliferation in vitro [30]. Our results revealed $t b \times 5$ insufficiency ultimately resulted in activation of apoptosis and inhibition of cell growth in whole individual of zebrafish embryo, though knockdown of TBX5 leads to overexpression of both anti-apoptotic and pro-apoptotic gene than wild type embryos and the controls. Those data implied that abnormal $t b \times 5$ level play a role in aberrant apoptosis and cell growth contributing to dysmorphogenesis.

\section{Conclusion}

In summary, abnormal appearances in zebrafish embryos with $t b x 5$ deficiency including string-like heart, curled trunk, curled tail, and pectoral fins might be a consequence of aberrant apoptosis and dormant cell growth in early embryonic development, which affected late differentiation and growth of organs as well as maturation.

\section{Acknowledgements}

The MF20 antibody developed by D.A. Fischman was obtained from the Developmental Studies Hybridoma Bank developed under the auspices of the NICHD and maintained by the University of lowa, Department of Biological Sciences, lowa City, IA 52242.

\section{Author details}

'Department of Pediatrics and Pathology, Taipei Veterans General Hospital, Taipei, Taiwan. ${ }^{2}$ School of Medicine, National Yang Ming University, Taipei, Taiwan. ${ }^{3}$ Department of Medical Research and Education, National YangMing University Hospital, Yilan, Taiwan. ${ }^{4}$ Laboratory of Molecular Biology, Institute of Aquaculture, National Taiwan Ocean University, Keelung, Taiwan ${ }^{5}$ Institute of Zoology, National Taiwan University, Taipei, Taiwan.

\section{Authors' contributions}

$J H L$ and $J K L$ conceived of the study, participated in its design, coordination and drafted the manuscript. TT participated in its design and drafted the manuscript, SC, SY and AY carried out the molecular genetic studies. RT and $\mathrm{HL}$ participated in its design and coordination. All authors read and approved the final manuscrpt.

\section{Competing interests disclosure}

The authors declare that they have no competing interests.

Received: 22 May 2011 Accepted: 8 October 2011 Published: 8 October 2011

\section{References}

1. Bruneau BG, Nemer G, Schmitt JP, Charron F, Robitaille L, Caron S, Conner DA, Gessler M, Nemer M, Seidman CE, Seidman JG: A murine 
model of Holt-Oram syndrome defines roles of the T-box transcription factor Tbx5 in cardiogenesis and disease. Cell 2001, 106:709-721.

2. Koshiba-Takeuchi K, Takeuchi JK, Matsumoto K, Momose T, Uno K Hoepker V, Ogura K, Takahashi N, Nakamura H, Yasuda K, Ogura T: Tbx5 and the retinotectum projection. Science 2000, 287:134-137.

3. Basson CT, Bachinsky DR, Lin RC, Levi T, Elkins JA, Soults J, Grayzel D, Kroumpouzou E, Traill TA, Leblanc-Straceski J, Renault B, Kucherlapati R, Seidman JG, Seidman CE: Mutations in human TBX5 [corrected] cause limb and cardiac malformation in Holt-Oram syndrome. Nat Genet 1997, 15:30-35.

4. Li QY, Newbury-Ecob RA, Terrett JA, Wilson DI, Curtis AR, Yi CH, Gebuhr T, Bullen PJ, Robson SC, Strachan T, Bonnet D, Lyonnet S, Young ID, Raeburn JA, Buckler AJ, Law DJ, Brook JD: Holt-Oram syndrome is caused by mutations in TBX5, a member of the Brachyury (T) gene family. Nat Genet 1997, 15:21-29.

5. Garrity DM, Childs S, Fishman MC: The heartstrings mutation in zebrafish causes heart/fin Tbx5 deficiency syndrome. Development 2002, 129:4635-4645.

6. Lu JH, Lu JK, Choo SL, Li YC, Yeh HW, Shiue JF, Yeh VC: Cascade effect of cardiac myogenesis gene expression during cardiac looping in tbx 5 knockdown zebrafish embryos. J Biomed Sci 2008, 15:779-787.

7. Camarata T, Krcmery J, Snyder D, Park S, Topczewski J, Simon HG: Pdlim7 (LMP4) regulation of Tbx5 specifies zebrafish heart atrio-ventricular boundary and valve formation. Dev Biol 2010, 337:233-245.

8. Garg V, Kathiriya IS, Barnes R, Schluterman MK, King IN, Butler CA, Rothrock CR, Eapen RS, Hirayama-Yamada K, Joo K, Matsuoka R, Cohen JC, Srivastava D: GATA4 mutations cause human congenital heart defects and reveal an interaction with TBX5. Nature 2003, 424:443-447.

9. Hiroi Y, Kudoh S, Monzen K, Ikeda Y, Yazaki Y, Nagai R, Komuro I: Tbx5 associates with $\mathrm{Nk \times 2}-5$ and synergistically promotes cardiomyocyte differentiation. Nat Genet 2001, 28:276-280.

10. Boogerd CJ, Dooijes D, llgun A, Mathijssen IB, Hordijk R, van de Laar IM, Rump P, Veenstra-Knol HE, Moorman AF, Barnett P, Postma AV: Functional analysis of novel TBX5 T-box mutations associated with Holt-Oram syndrome. Cardiovasc Res 2010, 88:130-139.

11. Goetz SC, Brown DD, Conlon FL: TBX5 is required for embryonic cardiac cell cycle progression. Development 2006, 133:2575-2584.

12. Pyati UJ, Look AT, Hammerschmidt M: Zebrafish as a powerful vertebrate model system for in vivo studies of cell death. Semin Cancer Biol 2007 17:154-165.

13. Poelmann RE, Gittenberger-de Groot AC: Apoptosis as an instrument in cardiovascular development. Birth Defects Res C Embryo Today 2005, 75:305-313.

14. Bursch W, Oberhammer F, Schulte-Hermann R: Cell death by apoptosis and its protective role against disease. Trends Pharmacol Sci 1992, 13:245-251.

15. Cole LK, Ross LS: Apoptosis in the developing zebrafish embryo. Dev Biol 2001, 240:123-142.

16. Uchida D, Yamashita M, Kitano T, Iguchi T: Oocyte apoptosis during the transition from ovary-like tissue to testes during sex differentiation of juvenile zebrafish. J Exp Biol 2002, 205:711-718.

17. Molin DG, DeRuiter MC, Wisse LJ, Azhar M, Doetschman T, Poelmann RE, Gittenberger-de Groot AC: Altered apoptosis pattern during pharyngeal arch artery remodelling is associated with aortic arch malformations in Tgfbeta2 knock-out mice. Cardiovasc Res 2002, 56:312-322.

18. Fischer U, Schulze-Osthoff $\mathrm{K}$ : Apoptosis-based therapies and drug targets. Cell Death Differ 2005, 12(Suppl 1):942-961.

19. Gustafsson AB, Gottlieb RA: Heart mitochondria: gates of life and death. Cardiovasc Res 2008, 77:334-343.

20. Shoubridge EA, Wai T: Mitochondrial DNA and the mammalian oocyte. Curr Top Dev Biol 2007, 77:87-111.

21. Van Blerkom J: Mitochondria in human oogenesis and preimplantation embryogenesis: engines of metabolism, ionic regulation and developmental competence. Reproduction 2004, 128:269-280.

22. Pradelli LA, Beneteau M, Ricci JE: Mitochondrial control of caspasedependent and -independent cell death. Cell Mol Life Sci 2010, 67:1589-1597.

23. Ricci JE, Munoz-Pinedo C, Fitzgerald P, Bailly-Maitre B, Perkins GA, Yadava N, Scheffler IE, Ellisman MH, Green DR: Disruption of mitochondrial function during apoptosis is mediated by caspase cleavage of the p75 subunit of complex I of the electron transport chain. Cell 2004, 117:773-786.
24. Waterhouse NJ, Goldstein JC, von Ahsen O, Schuler M, Newmeyer DD, Green DR: Cytochrome c maintains mitochondrial transmembrane potential and ATP generation after outer mitochondrial membrane permeabilization during the apoptotic process. J Cell Biol 2001, 153:319-328.

25. Bradbury DA, Simmons TD, Slater KJ, Crouch SP: Measurement of the ADP: ATP ratio in human leukaemic cell lines can be used as an indicator of cell viability, necrosis and apoptosis. J Immunol Methods 2000, 240:79-92.

26. Lemasters JJ, Qian T, Bradham CA, Brenner DA, Cascio WE, Trost LC, Nishimura Y, Nieminen AL, Herman B: Mitochondrial dysfunction in the pathogenesis of necrotic and apoptotic cell death. J Bioenerg Biomembr 1999, 31:305-319.

27. Gustafsson AB, Gottlieb RA: Mechanisms of apoptosis in the heart. J Clin Immunol 2003, 23:447-459.

28. Halestrap AP: Calcium, mitochondria and reperfusion injury: a pore way to die. Biochem Soc Trans 2006, 34:232-237.

29. Mahyar-Roemer M, Katsen A, Mestres P, Roemer K: Resveratrol induces colon tumor cell apoptosis independently of p53 and precede by epithelial differentiation, mitochondrial proliferation and membrane potential collapse. Int J Cancer 2001, 94:615-622.

30. He ML, Chen Y, Peng Y, Jin D, Du D, Wu J, Lu P, Lin MC, Kung HF: Induction of apoptosis and inhibition of cell growth by developmental regulator hTBX5. Biochem Biophys Res Commun 2002, 297:185-192.

\section{doi:10.1186/1423-0127-18-73}

Cite this article as: Lu et al: Induction of apoptosis and inhibition of cell growth by tbx5 knockdown contribute to dysmorphogenesis in Zebrafish embryos. Journal of Biomedical Science 2011 18:73.

\section{Submit your next manuscript to BioMed Central and take full advantage of:}

- Convenient online submission

- Thorough peer review

- No space constraints or color figure charges

- Immediate publication on acceptance

- Inclusion in PubMed, CAS, Scopus and Google Scholar

- Research which is freely available for redistribution

Submit your manuscript at www.biomedcentral.com/submit
() Biomed Central 